\title{
Ж.В. Посконная
}

\section{ТРАДИЦИОННОЕ МИРОВОЗЗРЕНИЕ АЛТАЙЦЕВ: КУЛЬТ ВОДЫ И ФЕНОМЕН ЖИЗНИ}

\begin{abstract}
Данная работа посвящена культу воды у алтайцев, рассматриваемому в культуре означенного этноса как часть совокупности представлений об одушевлённости всего окружающего мира и тесно связанному с пониманием такого феномена, как жизнь. Исследуемый в статье культ - это достаточно уникальное явление, так как он является не просто ушедшим в далёкое прошлое своеобразным культурным "артефактом», находящим логическое продолжение в литературных источниках, а представляет собой живую и успешно функционирующую в наше время традицию. Автором особо акиентируется внимание на том, что культ воды для алтайского этноса выступает не просто одним из многочисленных сакральных символов и хранителей жизни, но является важным сущчностным моментом традиционного мировосприятия и мировоззрения.

Ключевые слова: феномен жизни, культ воды, традиционное мировоззрение, алтайский этнос, мифоритуальная традиция, обрядовая символика.
\end{abstract}

В настоящее время в сфере культуры отмечаются две противоположные тенденции: обезличивание, вытеснение массовой культурой традиционной культуры, утрата связей со своей историей и национальными традициями, с одной стороны, и проявление интереса к национальной культурной самобытности различных этносов, усиление этнических чувств, проявляющихся во всех сферах человеческой жизни, - с другой. Поэтому в большинстве регионов нашей страны отмечается процесс этнического возрождения, идущий параллельно с мировыми глобализационными процессами. В связи с этим наблюдается повышенный интерес к таким локальным проблемам этнической культуры, как различные культы в традиционном мировоззрении. Данная тематика достаточно успешно уживается с традиционными направлениями исследований, и численность работ, затрагивающих в той или иной степени проблематику культов огня, гор, деревьев и т.д. в традиционном мировоззрении различных этносов, постоянно растёт, включая в себя разные исторические периоды и новые аспекты.

Сегодня, в рамках возрождения интереса к данной теме, возвращаются имена тех, кто одним из первых стал проявлять интерес к культу воды у алтайцев, - это А.В. Анохин [1], В.И. Вербицкий [2], Л.П. Потапов [3]. Многое для понимания ритуалов и обычаев, связанных с водой, было сделано такими исследователями и собирателями народного фольклора, как Б.Я. Бедюров [4], Н.П. Дыренкова [5], В.П. Дьяконова [6], Е.Е. Ямаева [7].

По верованиям алтайцев, здоровым, а значит, наполненным жизненной силой человеком, может считаться только тот, кто живёт в гармонии и согласии со всеми окружающими мирами: Вселенной (Орчылан), Землёй (Јертелекей), родиной (Алтай), а также ведёт именно такой образ жизни, который соответствует нормам традиционной культуры. 
Природа для алтайского этноса служит его мировоззрением и философией, основой нравственности и действия, критерием и оценкой его взаимоотношений с окружающей средой, внешним и внутренним миром [8. С. 17-19]. Любовью и уважением к окружающей среде проникнуто традиционное сознание в целом. Каждодневное общение человека с природой строго регламентировано. Коренное население Горного Алтая всегда относилось с уважением к природе, ценило ее. Данное почитание нашло отражение в национальной культуре, нравах и обычаях. Мифологические представления алтайцев о мире и Вселенной невольно и непосредственно отражают своеобразие ландшафта Алтайского края. Согласно религиозно-мифологическим представлениям данного этноса, каждое живое существо, растение, природная стихия или даже предмет - живые и имеют душу. Поэтому основой верований алтайцев является убеждённость в том, что природа и всё, что её составляет, - это единое живое существо. У алтайских народов испокон веков каждый предмет был одушевлён и почитаем, наделён антропоморфными чертами, и общение с ним как с представителем «мира природы» должно было соответствовать всем моральным и этическим нормам, изначально закреплённым традицией [9. С. 198-201]. Традиция антропоморфизации природы в мировосприятии алтайцев обосновывается синкретизмом традиционного сознания, основанного на взаимопроникновении «мира природы» и «мира людей». Данная идея продуцировалась у народов Алтая во все времена на разных уровнях, выражаясь лишь разными символами, но, вероятно, только такой способ упорядочения окружающего хаоса придавал мировоззрению данных этносов всеобщность и несомненную схожесть в традициях и культуре.

В данной работе мы подробнее остановимся на культе воды у алтайцев, составляющем один из важнейших аспектов самой природы и сопровождающем человека всю его сознательную жизнь, проходя все сферы производственной и духовной деятельности.

Связь культа воды как части совокупности представлений об одушевлённости всего окружающего мира с феноменом жизни в традиционном мировоззрении алтайцев нами освещена в нескольких аспектах, в которых, по нашему мнению, особо акцентируется внимание на том, что культ воды для алтайского этноса выступает не просто одним из многочисленных сакральных символов и хранителей жизни, но является важным, сущностным моментом традиционного мировосприятия и мировоззрения.

Женский образ духа воды. У алтайцев каждые река, родник, озеро имеют свою хозяйку «Суу-ээзи» («Дух воды»), которая представляется в виде девицы, женщины или старушки. По мнению Н.Ф. Катанова и многих других исследователей, часто этот дух выступает в образе девицы с рыжими волосами, которая, сидя на берегу реки, расчёсывает их гребнем. Она притягивает к реке мужчин, и увидевшие её мужчины неудержимо будут тянуться к воде [10. C. 29-31]. Самые большие реки Катунь, Бия, Чулышман, Чуя, Башкаус, Чарыш имеют хозяек ханского происхождения. Кроме того, часто у алтайцев таким крупным рекам, как Катунь, даются особые сакральные имена, связанные с образом Вселенской матери - «Эне-Кадын киндикту» (Мать-Катунь, имеющая пуповину). Именно через эту пуповину реки, по традиционному мировоззрению алтайцев, питают водой, а значит самой жизнью, землю. 
Женский образ, тем более образ матери, всегда олицетворял духа воды в традиционном сознании алтайцев не случайно, так как только женщина и мать могут принести в этот мир новую жизнь, поддерживать эту жизнь с помощью своего материнского молока (в данном случае воды), не дать жизни угаснуть и содействовать её благополучию.

Дух Суу-ээзи управляет всеми водами. Чтобы не разгневать его, алтайцы приносят этому духу жертвы, не загрязняют водоёмы, относятся к хозяину уважительно и с почтением. Суу-ээзи может как помочь, даровать удачу, здоровье, долголетие, так и наказать людей за пренебрежительное отношение наслать наводнение или даже отнять жизнь. У алтайцев о реке говорят как о живой: начало реки - это «голова», река «выходит из-под земли», «вода держит землю» (реки и озёра под землёй связаны между собой). Кроме того, начало реки у алтайцев связано с образом «пупа земли», «мировой горы». Например, главная река Алтая Катунь зарождается у самой значимой вершины Сибири - Белухи. Алтайцы называют эту мировую гору «Кадын-Бажы УчСумер» (Исток Катуни Трёхвершинный), а мировую реку с уважением величают как «Эне-Кадын киндикту» (Мать-Катунь, имеющая пуповину, т.е. вершину). В семантике этих названий прослеживается сакральная связь горы и реки как небесного мира и земной жизни.

Вода как первооснова Вселенной. При рассмотрении культа воды и такого феномена, как жизнь, заслуживает особого внимания алтайская легенда о сотворении Вселенной. В алтайской версии представлений о Вселенной её первичным материалом являлось огромное водное пространство - мировое озеро, где находилась «священная мать» Умай-эне - символ животворящего женского начала, прародительница всего живого на земле, принимавшая непосредственное участие в сотворении сначала земли, а затем и неба. «На третьем слое неба белеет молочное озеро - Сут-кӧль - чистый и первозданный источник всей жизни. В озере беззаботно и беспечно плескаются будущие жизни, которые охраняют хозяин озера - синий бык, сидящая на Сурунгоре золотоволосая богиня-мать Умай-эне и рыба Кер-балык...» [11. С. 157159]. Молочное озеро, как и само молоко, всегда являлось символом душевной чистоты и святости у кочевников Центральной Азии, и, по мировоззрению алтайцев, именно с этим небесным озером связана жизнь на земле. Поэтому алтайцы-шаманисты всегда возлагали все свои самые сокровенные чаяния и надежды на всеобщую мать-прародительницу Умай-эне и рыбу Кер-балык. Кроме того, с помощью этого священного озера алтайские камы (шаманы) могли получать информацию о зародышах (кут) на скот, зародышах (јула) на детей. Данное легендарное озеро Сут-кӧль, по представлениям алтайцев, одаривает землю особой животворящей силой, способной к зачатию и рождению любых земных существ. Кроме того, по представлению коренных народов Алтая, ещё до сотворения Вселенной именно из воды бог верхнего мира Ульгень вытащил кусок глины, из которой впоследствии слепил человека. Следовательно, вода, по мнению алтайцев, при создании Вселенной первична, она является источником Вселенной, а значит, источником и первоосновой самой жизни. Именно такой вывод помогают сделать алтайские мифы о сотворении Вселенной, которые в разных вариантах развивают 
идею живительной силы влаги (воды, слёз, молока) и отражают жизнеприносящую функцию воды.

Вода в жизненном ичикле. В мифах Алтая вода, как и сама жизнь, может рассматриваться в двух ипостасях: во-первых, вода - это аналог первобытному хаосу, который существовал ещё до начала мироздания, а во-вторых, - это стихия, связанная с рождением, созиданием и смертью. Исходя из теории А.М. Сагалаева, который на основе этнографических исследований реконструировал картину мира урало-алтайских народов, трактовка «жизни» у алтайцев является движением во времени и пространстве, а жизнь человека движением, имеющим протяженность [12. С. 153-154]. По миропониманию алтайцев, это движение совершается не по прямой линии, а по замкнутому кругу земного бытия, где человек последовательно проходит несколько стадий своего развития: от младенца до глубокого старика.

Таким образом, прошлое не может быть отделено от будущего, а тем более настоящего; умершие - от живых, новорожденные - от стариков и т.д. Именно так представлена вышеописанная мифологическая ритуальная схема, которая свойственна бытию алтайцев. В данной концепции смерть сравнима с зачатием жизни, т.е. инобытием. Подобный круговорот жизни и смерти можно проследить в алтайских мифах о реках, где реки выступают своеобразной дорогой, связывающей воедино «верх» и «низ», т.е. жизнь и смерть [Там же. С. 157-160]. Следовательно, согласно мифологии алтайцев, жизнь на земле, двигаясь по замкнутому кругу и соприкоснувшись в своём движении со смертью, не прекращается, а, наоборот, между данными противоположными гранями бытия существует тесная сакральная взаимосвязь.

В мифоритуальной традиции алтайского этноса, связанной с культом воды и таким феноменом, как жизнь, самыми значимыми в жизни человека являются первые дни, недели и месяцы после рождения. Данное положение связано с тем, что ребенок некоторое время после своего появления на свет, по вере алтайцев, является ещё не полноправным представителем их общества, инаковым существом, как бы не принадлежащим в полной мере миру живых. По этой причине в период «кабай бала», или как его ещё принято называть на Алтае колыбельный период, ребёнку покровительствует сама Умайэне - «священная мировая мать», непосредственно связанная с первозданным водным источником всей жизни на земле. Именно ей посвящены многочисленные «алкыш сӧс» (благопожелания), служившие важными оберегами для младенца в этот сложный период жизни.

Спустись, покрой и будь матерью!

Смывшая грязь в озёрной воде,

Обрезавшая пуповину белой щепкой,

Имеющая питьё в озере,

Имеющая игрища на Сурун-горе,

С гребневидными волосами Умай-эне,

Среди сорока девиц,

Чистая дева Умай-эне! [13. С. 18].

Кроме того, известен ритуал приобщения младенца к покровителям рода - «Ак-Сумер» и «Агын-суу», дающий, по представлениям алтайцев, гарантию сохранения и благополучия ребёнка на жизненном пути. Олицетворение 
«Ак-Сумер адан болзын, Агын-суу энен болзын» («Пусть гора Ак-Сумер будет отцом, Река будет матерью»), применяемое в данном ритуале, оживляет и одухотворяет неживой мир, придавая тем самым «алкыш сӧс» - большую поэтичность. Гора Ак-Сумер здесь олицетворяет отца, река Агын суу - мать как символ женского начала, дарующий жизнь всему сущему.

Обрядовая символика, связанная с водой. В многочисленных литературных источниках достаточно показательно излагаются данные об обычаях и обрядах саяно-алтайских народностей в весенний период времени, связанных с культом рек и приуроченных прежде всего к моменту прохождения льда, оживления природы после зимы [10. С. 32-33]. В этот момент важно было вступить во взаимоотношения с речными и озёрными духами, просить их о плодородии и проводить обряды жертвоприношения, ведь именно в весенний период жизнь в природе начинает набирать полную силу.

Часто в ритуальных благопожеланиях неодушевленные предметы и природные явления сравниваются алтайцами с существами из живого мира. Так, принимая за основу полевые материалы В.И. Вербицкого, учёные отмечают, что у алтайских народов имело место такое понятие, как «кут» - некая сверхъестественная сила, дающая жизнь всему сущему на земле. В весенних молениях, например, старший в роду или кам (шаман) обращались к Јер-Суу (Земля-Вода) и к Тӧс-Туу (гора-покровитель) для того, чтобы получить «кут» (т.е. саму жизнь) для людей и животных как залог благополучия и процветания роду. В мифологическом мировоззрении «Тӧс-Туу» (родовая гора) воспринимался как старейший основатель рода, созидающее мужское начало, а «суу» - река (вода) - как женское, потому как только этим двум началам уготована роль зачинателей новой жизни на земле. Анализируя подобные обряды, такие исследователи, как А.В. Анохин, В.И. Вербицкий, отмечали, что практически всегда традиционное сознание алтайцев-шаманистов помещает источник жизни как бы за пределами общества, а зачатие новой жизни, по мировоззрению данного этноса, осуществимо только после обращения человека к силам природы [2. С. 65-67]. Созидательную, животворящую силу духа воды и духа горы, тесно связанных между собой самой жизнью, характеризует один из примеров эпического сказания «Маадай-Кара». В данном случае дух горы рождает героя, а дух воды - богатырского коня:

\section{Карыш-Кулак тёмно-гнедой - \\ Его создатель - дух воды. \\ Маадай-Кара алып седой - \\ Его создатель - дух горы [14. С. 17].}

Именно потому, что воде на Алтае приписывалась способность соединять прошлое, настоящее и будущее, мир живых и мир мёртвых, она всегда занимала существенное место в погребальных обрядах данного этноса. В связи с этим сформировался довольно развитый культ мёртвых, жертвоприношения и моления которого напрямую зависели от реки или других видов гидросистем.

С водой и всеми видами водоёмов у алтайского народа связаны также представления об устройстве мира мёртвых, где у большей части водоёмов нет собственных имён и названий. Однако все они обладают цветовыми 
и цифровыми маркерами, несомненно, очень важными для понимания представлений алтайцев о таких феноменах, как жизнь и смерть. В нижнем мире, находящемся под властью бога Эрлика, все водоёмы являются поглотителями душ людей. В этом же мире на реке Тойбойдым, по представлениям алтайцев, живут водяные чудовища - Абра и Тутпалар, охраняющие дворец самого Эрлика и души умерших. Души, как полагали шаманы, срывались в реку Тойбойдым с волосяного моста, и возврат их обратно в мир живых был уже невозможен.

По поводу названия водоёма Тойбойдым у учёных имеется несколько расхожих мнений. Дословно данное название означает «не насытилась», так как, по представлениям алтайских шаманов, эта мифическая река вбирает в себя всё негативное и отрицательное, т.е. противное жизни [15. С. 152-153]. Миссионер В. Вербицкий этим термином пользовался просто при обозначении Мирового океана и реки Обь. Согласно мифологии алтайцев - это очень большое, не имеющее дна море. Река Тойбойдым, по мифоритуальной традиции алтайцев, наполнена слезами и кровью живых и мёртвых людей. В отношении слёз установлена связь данной мифической реки с погребальным обрядом многих тюркских народов (тувинцев, телеутов, теленгитов, алтайкижи), у которых оплакивание умерших носило древнюю традицию [1. С. 121]. Слёзы живых и мёртвых, по религиозным представлениям алтайцев, в реке Тойбойдым смешиваются, и только так почивший слышит добрые слова своих живых родственников, что приносит ему утешение и радость в мире мёртвых. Из этого можно сделать вывод, что слёзы в реке Тойбойдым - знак, кодирующий связь живых и мёртвых, разрываемую затем временным фактором через определённые ритуалы, условно называемые поминальными циклами.

Кроме того, у алтайцев известен ритуал, когда после гибели на воде ребёнка его отец весной отправлял на плоту по течению реки в нижний мир одежду для него и жертвенные дары для хозяина нижнего мира. Повидимому, именно так в общетюркской картине мира представлялась ощутимая граница реальной земной жизни, за которой мог оказаться вход в подземный мир, куда отправлялись все жертвенные подношения.

Таким образом, река (вода) в данных случаях выступает в роли медиатора между миром живых и миром мёртвых, а следовательно, между самой жизнью и смертью.

Лечебная функция воды. Вода воспринималась алтайцами как единство, основанное на многообразии, которое питать могла только природа. Поэтому именно на природу была возложена «ответственность» за бытие и именно к ней обращались алтайцы в трудные моменты жизни и при болезнях.

До сих пор у современных алтайцев большое значение придаётся почитанию целебных источников-аржанов. Известно, что алтайцами почитается даже не сам источник как таковой, а дух-хозяин каждого конкретного источника. Поэтому лечебное действие приписывается именно духу источника (Сууээзи), который обладает известной целительной силой, а не просто воде в самом источнике. По одной алтайской легенде все аржаны появились из ран великолепного богатырского коня, убитого людьми. От этой воды, которая полилась из ран вместо крови, у людей стали затягиваться раны и исчезать 
болезни. Так, по представлениям алтайцев, и возникли целебные аржаны, которые народ стал почитать как священные источники, дарующие энергию, молодость и чудодейственную силу жизни [16. С. 112-114].

Сегодня известно, что целебные источники Алтая различны по составу, содержат серебро, радон, сероводород и другие химические элементы. Но ещё задолго до появления современной науки с её возможностями в проведении химического анализа воды местное население Алтая всегда знало, в каком именно источнике можно излечиться от той или иной болезни [17. C. 274].

Период, наиболее подходящий для посещения аржана, как считают алтайцы, начинается с начала лета, когда распускаются листья на деревьях (јажыл бурде - «зелёный лист»), и заканчивается в середине осени, когда листва становится жёлтой (сары бурде - «жёлтый лист»). Благоприятными для этого обряда часами традиционно считается время от двенадцати до двух часов дня, т.е. когда солнце достигло своего зенита и может проявить наибольшую активность. Данный период и время для посещения целебного источника, по нашему мнению, были выбраны алтайцами не случайно, так как именно тогда природа достигает наивысшего пика своего расцвета и полна жизненной силы, которую потом сможет через целительный источник передать человеку.

При посещении аржанов алтайцами до сегодняшнего дня совершается особый обряд привязывания ритуальных ленточек (кыйра) разных цветов. Каждый цвет кыйра имеет своё предназначение. Белый (цвет самих Аржансуу) - цвет молока, вскормившего весь человеческий род, а значит, давший человеческому роду саму жизнь. Жёлтый - цвет солнца и луны, розовый цвет символизирует огонь, голубой - небо и звёзды. Зелёный цвет - это цвет листьев, трав, священных растений можжевельника (арчына) и кедра [18. С. 128]. Как видим, все эти цвета у алтайцев теснейшим образом связаны с природой, т.е. с самой жизнью.

На заключительном этапе, после обряда поклонения и завершения всех лечебных процедур, люди в алкышах-благопожеланиях выражают свою благодарность природе, Алтаю как обладателям целебных горных источников, дарующих любому доброму человеку в отдельности и всему народу в целом мир, благополучие, здоровье и саму жизнь.

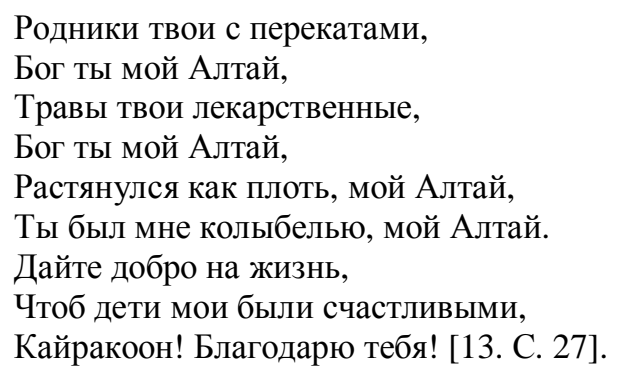

Интересен ещё тот факт, что, по традиционным верованиям алтайцев, вода или снег могут одарить не только крепким здоровьем, но и служат для скорого возрождения убитого животного или пойманной рыбы. Поэтому останки убитых животных алтайцы зачастую закапывали в снег или ледники, 
а рыбные потроха и чешую бросали в проточные реки, надеясь на их скорое возрождение, от которого зависела сытная и благополучная жизнь самого охотника, его семьи и рода в целом.

Запреты, связанные с водой. Несмотря на рациональный характер многих запретов, связанных, в частности, с водой (например, не кричать рядом с водоёмом, не загрязнять его), необходимых в быту для успешной рыбалки и охоты, данные запреты изначально всё же предназначались для того, чтобы оберегать покой и благополучие духов-хозяев. Человека, нарушившего эти запреты, духи воды, по мнению алтайцев, могли подвергнуть различным наказаниям: лишить добычи, помешать охотнику хорошо прицелиться, наслать плохую погоду и вообще сделать невозможным пребывание в тайге и горах. Однако следование исстари сложившемуся комплексу морально-нравственных рациональных и иррациональных правил и установок на практике позволяло алтайцам сохранять экологический баланс в природе. К этому можно добавить, что весь комплекс данных правил-запретов является не столько экологической культурой, сколько народной природоохранной традицией, нацеленной на сохранение мест обитания человека, т.е. на продление жизни как отдельного человека, так и всего рода в целом.

Как правило, определённые нормы поведения всегда являлись непоколебимой основой любого тематического комплекса примет и поверий, от соблюдения или несоблюдения которых зависела и зависит жизнь человека традиционного общества и той природной среды, с которой он соприкасается. Данная установка формирует немало особых законов и предписаний, касающихся одухотворённой, т.е. наполненной жизненной силой реки. Наиболее значимыми, по мнению исследовательницы Н.А. Тадиной, являются два из них: во-первых, ни при каких жизненных обстоятельствах нельзя ругать реку, а во-вторых, пренебрегать даже самой мелководной рекой не следует [19. C. 147-148].

Кроме того, существуют строгие табу на попытки испражнения вблизи источников или в воды священного озера, реки или ручья. Около водоёма или в тайге во время охоты нельзя ссориться, сквернословить или ругаться. Также строго запрещено плевать в воду, думать о плохом у реки, осквернять культовые сооружения, возведённые в честь священных источников, и т.д. По мировоззрению алтайцев, река может наказать преступившего эти запреты, отняв здоровье, удачу на охоте и рыбалке, а порой и саму жизнь.

Кроме того, по мировоззрению алтайцев, начало реки соприкасается с неким сакральным центром, недоступным и непостижимым для обычного человека. Сама же река ассоциируется с «дорогой в заданном направлении», по берегам которой неспешно течёт земная жизнь, по дну же пролегает запретный для живых путь в иной мир. Водная стихия у алтайцев - это особый противоположный мир, поэтому вода может кардинально менять состояние человека в зависимости от его самочувствия: сделать больного здоровым и наоборот.

Ко всему прочему, река для алтайского этноса - это ещё и своеобразная «граница миров», где полярные по своей сущности миры, находящиеся на разных берегах, разделяются самой рекой. Так, например, если какую-либо семью или целый род преследуют несчастья и неудачи, то нужно всего лишь 
переселиться на другой берег реки, и река в скором времени непременно вернёт удачу и благополучие всем, кто переправился через неё [19. С. 149-151].

Экологические традиции, состоящие из вышеперечисленных запретов и предписаний, связанных с водой, как и все элементы традиционной культуры, отражают идеалы, стереотипы поведения, ценностные ориентации народа, передающиеся из поколения в поколение. Ведь именно от сохранности и благополучия природы зависит благополучие и здоровье человека, а значит, и его жизнь.

Итак, религиозные и мифологические представления алтайского народа подтверждают их тесную взаимосвязь с природой. Алтайцы с древних времён и до наших дней почитают природу как человека, и, по их представлениям, природа и всё, что связано с ней, живое и, подобно живому существу, рождается, существует и умирает. Она служит для алтайского народа источником энергии, гарантом жизни, поддержания здоровья и благополучия. Поэтому обожествление природы своего края, конкретных рек, озёр, гор и даже отдельных деревьев является для алтайцев столь же естественным, как и сама жизнь.

\section{Лuтература}

1. Анохин А.В. Материалы по шаманству у алтайцев, собранные во время путешествий по Алтаю в 1910-1912 гг. по поручению Русского комитета для изучения Средней и Восточной Азии. Горно-Алтайск : Ак-Чечек, 1994. 248 с.

2. Вербицкий В.И. Алтайские инородцы: Сборник этнографических статей и исследований. Новосибирск: Смысл, 1992. 267 с.

3. Потапов Л.П. Традиционная народная культура алтайцев - наследница древней цивилизации кочевников Центральной Азии // Народы Сибири: история и культура. Новосибирск : Институт археологии и этнографии СО РАН, 1997. С. 22-30.

4. Бедюров Б.Я. Слово об Алтае. Ч. ІІ: История, фольклор и культура. Горно-Алтайск: ГУ книжное издательство «Юч-Сумер - Белуха» Республики Алтай, 2003. 527 с.

5. Дьренкова Н.П. Материалы по шаманству у телеутов // Сб. МАЭ. М.; Л., 1949. Т. Х. C. $108-190$.

6. Дьяконова В.П. Алтайцы (материалы по этнографии теленгитов Горного Алтая). Горно-Алтайск : Горно-Алтайское республиканское книжное изд-во «Юч-Сюмер», 2008. $223 \mathrm{c}$.

7. Ямаева E.E. Алтай сокровенный : традиционная и новая модель // Межкультурный диалог на евразийском пространстве. Древности Сибири и Центральной Азии. Горно-Алтайск: РИО ГАГУ, 2013. № 6 (18). С. 126-129.

8. Алёнышева И.Н. Экологический аспект в мировоззрении алтайцев // Вестник Томского государственного университета. Бюллетень оперативной научной информации. Томск : ТГУ, 2006. № 117: Вопросы изучения экологии и биоразнообразия Горного Алтая. С. 15-21. 206.

9. Никишенков А.А. Традиционный этикет народов России ХІХ-ХХ вв. М., 1999. С. 197-

10. Наследие Н.Ф. Катанова : история и культура тюркских народов Евразии : Доклады и сообщения Международного научного семинара, 30 июня - 1 июля 2005 г. / ред. коллегия : Р.М. Валеев, М.З. Закиев, Д.Г. Зайнуллин. Казань: Алма Лит, 2006. С. 28-39.

11. Радлов В.В. Мифология и миросозерцание жителей Алтая. М.: Наука, 1989. 175 с.

12. Сагалаев А.М. Алтай в зеркале мифа. Новосибирск : ЮКЭА, 1992.176 с.

13. Кандаракова E.H. Алтайские благопожелания и обряды их исполнения. ГорноАлтайск: Ак-Чечек, 1993. 205 с.

14. Маадай-Кара. Алтайский героический эпос / запись текста, перевод на русский язык и прил. С.С. Суразакова. М. : Главная ред. восточной литературы изд-ва «Наука», 1973. 272 с.

15. Тадина Н.A. Река как образ родины у алтайцев // Реки и народы Сибири: сб. науч. статей / отв. ред. Л.Р. Павлинская. СПб. : Наука, 2007. С. 151-159. 
16. Мифы Алтайских гор. Горно-Алтайск: Ак-Чечек, 1994. 416 с.

17. Наева А.И. Обряды, посвящённые целебным источникам аржан-суу / А.И. Наева // Наука, культура, образование. Горно-Алтайск, 2002. № Ю/11. С. 273-275.

18. Тюхтенева С.П. Архаические элементы в современном мировоззрении алтайцев: дис. ... канд. ист. наук. М.: Наука, 1996. 141 с.

19. Тадина Н.А. Картина мира как основа коммуникативной культуры алтайцев // Вестник археологии, антропологии и этнографии. 2011. № 1 (14). С. 146-153.

Poskonnaya Jeanna V. Municipal state-financed educational institution «Gymnasium № 25» (Kemerovo, Russian Federation).

E-mail:pgv9@bk.ru

Tomsk State University Journal of Cultural Studies and Art History, 2017, № 26, pp. 58-67.

DOI: $10.17223 / 22220836 / 26 / 6$

TRADITIONAL IDEOLOGY OF THE ALTAIANS: CULT OF WATER AND PHENOMENON OF LIFE

Key words: phenomenon of life, cult of water, traditional ideology, Altai ethnos, myth and ritual tradition, ritual symbols.

The work is devoted to the cult of water in Altai, considered in the culture of aforesaid ethnos as part of a set of ideas about the animation of the whole surrounding world and closely associated with the understanding of such phenomena as life. The cult researched in the article - a quite unique phenomenon, since it is not just peculiar cultural "artifact" which had become a thing of the past and finding its logical continuation in the literature sources, but a lively and successfully functioning tradition these days. The author particularly focuses on the fact that for Altai ethnos the cult of water serves not just one of the many sacral symbols and life savers, but it is an important, essential point of traditional ideology and world outlook. In the article the author analysis of various aspects of the issue is introduced, where a connection between life phenomenon and cult of water is revealed, involving various phenomena of the material and spiritual culture of The Altaians: "Female image of a water spirit", "Water as a fundamental principle of the Universe", "Water in a life cycle," "Ritual symbols associated with water", "Healing properties of water"," Prohibitions related to water". In the first aspect special attention is given to an image of "water spirit" (Suu-Eezi) and feminine side associated with vital force of water and characterized by ambivalent properties as a source of life itself as well as its destroyer. In the second aspect it is noted that in universal system of notions about the origin of the Universe a primary material for its creation in the Altaic version it was a water element, from which the progenitress of all life on Earth appeared - Umai-Ene ( "Holy Mother"). In the third aspect the emphasis is on the fact that in the myth and ritual conception of the Altaians' existence the water as life itself is dual: not only it is an equivalent of the primeval chaos existed long before creation of the Universe, but also the element associated with birth, creation and death. In the fourth aspect water is regarded as one of the mediators connecting the world of the living with the world of the dead determining all the basic living conditions of the Gorny Altai population. And in that capacity this element is analyzed as part of a series of ritual actions connected with birth, awakening of nature in spring, and also with an ancient Funerary Culture of the Altaians. The fifth aspect highlights the healing properties of water combining real medical effects with the magical ones. In the sixth aspect the taboos and restrictions of various kinds associated with water are recorded. The article is based on both the attracting a wide range of academic research materials among which the works of A.V. Anokhin, V. I. Verbitsky, E.N. Kondarakovoy are notable and the examples of the Altai folk sources.

\section{References}

1. Anokhin, A.V. (1994) Materialy po shamanstvu u altaytsev, sobrannye vo vremya puteshestviy po Altayu v 1910-1912 gg. po porucheniyu Russkogo komiteta dlya izucheniya Sredney $i$ Vostochnoy Azii [Materials on shamanism among the Altaians, collected during travels in Altai in 1910-1912. On behalf of the Russian Committee for the Study of Central and East Asia]. Gorno-Altaysk: Ak-Chechek.

2. Verbitskiy, V.I. (1992) Altayskie inorodtsy: Sbornik etnograficheskikh statey $i$ issledovaniy [Altaic Non-Russians: Collection of ethnographic articles and studies]. Novosibirsk: Smysl.

3. Potapov, L.P. (1997) Traditsionnaya narodnaya kul'tura altaytsev - naslednitsa drevney tsivilizatsii kochevnikov Tsentral'noy Azii [Traditional folk culture of Altaians is the heir of the ancient nomadic civilization of Central Asia]. In: Derevyanko, A.P. (ed.) Narody Sibiri: istoriya i kul'tura 
[Peoples of Siberia: History and culture]. Novosibirsk: Institute of Archeology and Ethnography, SB RAS. pp. 22-30.

4. Bedyurov, B.Ya. (2003) Slovo ob Altae. Ch. II: Istoriya, fol'klor i kul'tura [A word about Altai. Part II: History, folklore and culture]. Gorno-Altaysk: Yuch-Sumer - Belukha.

5. Dyrenkova, N.P. (1949) Materialy po shamanstvu u teleutov [Materials on shamanism in the Teleuts]. In: Tolstov, S.P. MAE [Collection of the Museum of Anthropology and Ethnography]. Vol. 10. Moscow; Leningrad: USSR AS. pp. 108-190.

6. Dyakonova, V.P. (2008) Altaytsy (materialy po etnografii telengitov Gornogo Altaya) [Altaians (On ethnography of Telengits of Gorny Altai)]. Gorno-Altaysk: Yuch-Syumer.

7. Yamaeva, E.E. (2013) Altay sokrovennyy : traditsionnaya i novaya model' [Altai: The traditional and the new model]. Drevnosti Sibiri i Tsentral'noy Azii. 6(18). pp. 126-129.

8. Alenysheva, I.N. (2006) Ekologicheskiy aspekt v mirovozzrenii altaytsev [The ecological aspect in Altaian worldview]. Vestnik Tomskogo gosudarstvennogo universiteta. Byulleten' operativnoy nauchnoy informatsii. 117. pp. 15-21.

9. Nikishenkov, A.A. (1999) Traditsionnyy etiket narodov Rossii XIX-XX vv. [Traditional etiquette of the peoples of Russia in the 19th - 20th centuries]. Moscow: Staryi Sad. pp. 197-206.

10. Valeev, R.M., Zakiev, M.Z. \& Zaynullin, D.G. (eds) Nasledie N.F. Katanova: istoriya $i$ kul'tura tyurkskikh narodov Evrazii [N.F. Katanov's Heritage: History and culture of Turkic peoples in Eurasia]. Kazan: Alma Lit. pp. 28-39.

11. Radlov, V.V. (1989) Mifologiya i mirosozertsanie zhiteley Altaya [Mythology and world outlook of Altai people]. Moscow: Nauka. KEA.

12. Sagalaev, A.M. (1992) Altay v zerkale mifa [Altai in the mirror of myth]. Novosibirsk: Yu-

13. Kandarakova, E.N. (1993) Altayskie blagopozhelaniya i obryady ikh ispolneniya [Altai wishful thinking and their rites]. Gorno-Altaysk: Ak-Chechek.

14. Maaday-Kara. (1973) Altayskiy geroicheskiy epos [Altai heroic epic]. Translated into Russian by S.S. Surazakov. Moscow: Nauka.

15. Tadina, N.A. (2007) Reka kak obraz rodiny u altaytsev [The river as an image of the native land with the Altaians]. In: Pavlinskaya, L.R. (ed.) Reki i narody Sibiri [Rivers and peoples of Siberia]. St. Petersburg: Nauka. pp. 151-159. Chechek.

16. Anon. (1994) Mify Altayskikh gor [Myths of the Altai Mountains]. Gorno-Altaysk: Ak-

17. Naeva, A.I. (2002) Obryady, posvyashchennye tselebnym istochnikam arzhan-suu [Rituals dedicated to curative springs Arzhan-Suu]. Nauka, kul'tura, obrazovanie. 10/11. pp. 273-275.

18. Tyukhteneva, S.P. (1996) Arkhaicheskie elementy v sovremennom mirovozzrenii altaytsev [Archaic elements in the modern worldview of the Altaians]. History Cand. Diss. Moscow.

19. Tadina, N.A. (2011) Picture of the world as the basis of communicative culture with the Altai peoples. Vestnik arkheologii, antropologii i etnografii - Bulletin of Archeology, Anthropology and Ethnography. 1(14). pp. 146-153. (In Russian). 